doi:10.1016/j.jaci.2005.10.022

Copyright (c) 2006 American Academy of Allergy, Asthma and Immunology Published by Mosby, Inc.

Food allergy, dermatologic diseases, and anaphylaxis

\title{
Breast milk fatty acids and allergic disease in preschool children: The Prevention and Incidence of Asthma and Mite Allergy birth cohort study
}

\author{
Alet H. Wijga PhD ${ }^{a, *}$, Adriana C. van Houwelingen MD, PhD ${ }^{b}$, Marjan \\ Kerkhof MD, PhD $^{c}$, Cora Tabak PhD $^{a}$, Johan C. de Jongste MD, PhD ${ }^{d}$, Jorrit \\ Gerritsen MD, PhD ${ }^{\mathrm{e}}$, Hendriek Boshuizen PhD ${ }^{\mathrm{f}}$, Bert Brunekreef PhD $^{\mathrm{g}}$ and \\ Henriette A. Smit PhD ${ }^{a}$
}

${ }^{a}$ From the Center for Prevention and Health Services Research, National Institute for Public Health and the Environment, Bilthoven

${ }^{\mathrm{b}}$ Nutrition, Toxicology and Environment Research Institute, Maastricht University ${ }^{\mathrm{C} D e p a r t m e n t}$ of Epidemiology and Bio-informatics, University Medical Center Groningen, University of Groningen

${ }^{\mathrm{d} D i v i s i o n}$ of Respiratory Medicine, Department of Pediatrics, Erasmus Medical Center-Sophia, Rotterdam

${ }^{\text {e}}$ Beatrix Children's Hospital, University Medical Center Groningen, University of Groningen

fCentre for Information Technology and Methodology, National Institute for Public Health and the Environment, Bilthoven

${ }^{9}$ Institute for Risk Assessment Sciences, Utrecht University

Supported by The Netherlands Asthma Fund, The Netherlands Ministry of Spatial Planning, Housing and the Environment, The Netherlands Ministry of Health, Welfare and Sport, and Numico Research, The Netherlands.

* Reprint requests: Alet $\mathrm{H}$. Wijga, PhD, National Institute for Public Health and the Environment, Center for Prevention and Health Services Research (Pigeonhole 101), PO Box 1, 3720 BA

\section{Background}

Better understanding of the association between early life lipid intakes and the development of allergic diseases is needed.

\section{Objective}

We prospectively studied breast milk content of $n-6, n-3$, and trans fatty acids in relation to allergic symptoms at the ages of 1 and 4 years.

\section{Methods}

Fatty acid content was determined in breast milk samples of 265 (158 allergic and 107 nonallergic) mothers of children participating in the Prevention and Incidence of Asthma and Mite Allergy study. Outcome variables studied were parental reported eczema at age 1 year, eczema at age 4 years, asthma at age 4 years, and, in a subgroup of 133 children, sensitization at age 4 years. 


\section{Results}

In children of mothers with allergy, breast milk $n-3$ long chain polyunsaturated fatty acids and the ratio between n-3 and n- 6 long chain polyunsaturated fatty acids were inversely associated with asthma and with persistent symptoms (eczema at age 1 year and eczema at age 4 years and/or asthma at age 4 years), but no associations between breast milk fatty acids and sensitization were observed. In children of mothers with allergy, also trans fatty acids tended to be inversely associated with allergic symptoms. In children of mothers without allergy, no associations between breast milk fatty acids and allergic symptoms were observed, but a-linolenic acid $(18: 3 n-3)$ was positively associated with sensitization.

\section{Conclusion}

In susceptible infants, the risk to develop allergic symptoms, but not the risk of sensitization, was modified by intake of $n-3$ long chain polyunsaturated fatty acids through breast milk.

Abbreviations used: AA, Arachidonic acid (20:4n-6); ALA, a-Linolenic acid (18:3n-3); DHA, Docosahexaenoic acid (22:6n-3); EPA, Eicosapentaenoic acid (20:5n-3); FA, Fatty acids; LA, Linoleic acid (18:2n-6); n-3LCP, n-3 Long chain polyunsaturated fatty acid ( $=$ total $n-3$ polyunsaturated fatty acid minus alinolenic acid); n-6LCP, $\mathrm{n}-6$ Long chain polyunsaturated fatty acid (= total $n-6$ polyunsaturated fatty acid minus linoleic acid); OR, Odds ratio; PIAMA, Prevention and Incidence of Asthma and Mite Allergy; PUFA, Polyunsaturated fatty acids; SPT, Skin prick test

Diet is one of the aspects of lifestyle where clues for prevention of asthma and allergy are sought. However, many uncertainties still surround the relationship between diet and asthma and allergies. These include the role of breast-feeding, the role of different components of breast milk and of the later diet, the time in life when different dietary components exert their influence, and the question of differences in sensitivity to dietary influences between subgroups in the population. These issues have been addressed in several papers and reviews recently published in this Journal. ${ }^{1,2,3 \text { and } 4}$

Lipids are one of the dietary components that seem to offer promising opportunities to influence the development of asthma and allergies. Several hypotheses have been proposed on the role of dietary fatty acid (FA) in the development of allergic diseases and in the rising incidence of these diseases in industrialized countries. A high proportion of $n-6$ polyunsaturated FA (PUFA) in the diet, low intakes of n-3 PUFA, and high intakes of trans FA have been suggested as risk factors for allergic diseases. Hodge et al $^{5}$ hypothesized in 1994 that the increase in childhood asthma in affluent countries could be related to an increased consumption of oils rich in n-6 PUFA, such as linoleic acid, accompanied by a low intake of n-3 PUFA. Black and Sharpe ${ }^{6}$ elaborated on this hypothesis, suggesting that a fall in the consumption of saturated fat and an increase in the amount of n-6 PUFA in the diet, in combination with a decrease in the consumption of oily fish (a rich source of n-3 LCP), might explain the increase of asthma, eczema, and allergic rhinitis in the developed world. The hypothesis that diets high in marine n-3 PUFA could have a beneficial effect on asthma comes from the understanding of asthma as a chronic inflammatory disease and from epidemiological evidence that populations consuming such diets have relatively low incidences of inflammatory conditions such as rheumatoid arthritis. ${ }^{7}$ To 
explain the immunological effects of n-3 PUFA, several mechanisms have been proposed. Early explanations focused on the ability of n-3 PUFA to suppress the production of prostaglandin $E_{2}$, derived from arachidonic acid (AA;20:4n-6), and thus to suppress $T_{H} 2$ responses to allergens. However, it has not been proven that this is the mechanism underlying the associations observed in epidemiological studies. Rather, it has become clear that the interaction between n-6 and n-3 PUFA and the immune system as well as the role of prostaglandin $E_{2}$ are far more complex than previously supposed. Besides an effect on prostaglandin production, n-3 PUFA may influence the function of Toll-like receptors and thus affect the response of cells of the immune system to external stimuli, and they may also decrease transcription of proinflammatory genes. ${ }^{8,9,10}$ and 11

Besides the numerous observations published on n-3 and n- 6 PUFA and allergic disease, another finding relating FA to allergic disease was reported by Weiland et al. ${ }^{12}$ Using data from the International Study on Asthma and Allergy in Children, the authors described a positive ecological association between trans FA intakes and the prevalence of asthma, allergic rhinoconjunctivitis, and atopic eczema in 10 countries. So far, this association has not been investigated in subsequent epidemiological studies.

In a recent review of "Diet as a risk factor for atopy and asthma," Devereux and Seaton ${ }^{2}$ conclude that, whereas epidemiologic studies have reported associations between lipid intakes and asthma and atopic disease, intervention studies have generally been disappointing. They state that further research is needed, in particular on the role of diet during fetal and early life and on the issue of individual susceptibility.

Analysis of breast milk FA composition offers the opportunity to study FA intakes in the first months of life, a period that may be crucial for the development of allergy. A few studies on breast milk FA composition in relation to childhood allergy have been conducted. ${ }^{13}, 14,15,16,17,18$ and 19 In 2001, Duchén and Björkstén reviewed the studies available at that time and concluded that there was evidence for a relationship between the development of atopic disease in infants and low n3 LCP levels in maternal milk. ${ }^{20}$ Three more studies ${ }^{17,18}$ and 19 were published after this review, but conclusive evidence has not been obtained so far.

In the Prevention and Incidence of Asthma and Mite Allergy (PIAMA) study, breast milk samples were collected from 276 mothers. In a previous study, we compared breast milk FA concentrations in mothers with and without allergy ${ }^{21}$ We found no differences between the 2 groups except for a small but statistically significant difference in the mean ratio $n-6 L C P / 18: 2 n-6$ in their breast milk. In the current study, we assessed the relationship between the FA content of these mothers' breast milk and allergic symptoms in their children at the ages of 1 and 4 years.

\section{Methods}

\section{Design of the study}

This study is part of the PIAMA birth cohort study on incidence, risk factors, and prevention of asthma and inhalant allergy. At baseline, the PIAMA study population consisted of the children of 1327 allergic mothers and of 2819 mothers without allergy who were recruited from the general population during pregnancy. At the time of recruitment, the pregnant mothers filled in a validated short screening questionnaire on allergy. ${ }^{22}$ Mothers reporting at least 1 of the following: (a history of) asthma, current hay fever, current allergy for pets, or current 
allergy for house dust or house dust mite were defined as allergic, and mothers reporting that they had none of these were defined as nonallergic. The children were born in 1996/1997 and are being followed until the age of 8 years. The study protocol was approved by the medical ethics committees of the participating institutes. All parents gave written informed consent.

In the PIAMA study, data are collected mainly by questionnaires. In addition, all children of mothers with allergy $(n=1327)$ and a random sample of 663 children of mothers without allergy were selected for home visits. When the infants were about 3 months old, 1860 families (93\% of those selected for home visits) were visited at home for the collection of house dust samples. At that time, 661 of the mothers who were visited were still breast-feeding, and 276 of them were willing and able to produce a milk sample for the breast milk study. Data on disease outcomes were missing or incomplete for 11 of their children, resulting in a study population of 265 children (158 with a mother with allergy and 107 with a mother without allergy).

\section{Exposure assessment}

Breast milk samples were collected either by manual expression or by breast pump, depending on the preference of the mother. The samples were put into tubes containing $2 \mu \mathrm{L}$ butylated hydroxyl toluene solution $(500 \mu \mathrm{g} / \mathrm{mL})$ to prevent oxidation. They were sent by mail to the National Institute of Public Health and the Environment and stored there at $-70^{\circ} \mathrm{C}$. FA composition of the breast milk was determined by gas liquid chromatography, as described by Foreman-van Drongelen et al. ${ }^{23}$ Details of breast milk collection and analysis have been reported elsewhere. ${ }^{21}$

To assess evidence for the hypotheses described in the introduction, the following FA and ratios were selected as exposure variables (out of the total number of 34 individual FA measured): linoleic acid (LA; 18:2n-6), a-linolenic acid (ALA; 18:3n3), AA (20:4n-6), eicosapentaenoic acid (EPA; 20:5n-3), docosahexaenoic acid (DHA; $22: 6 n-3)$, total $n-6 L C P$, total $n-3 L C P$, the ratio ALA/LA $(18: 3 n-3 / 18: 2 n-6)$, the ratio EPA/AA $(20: 5 n-3 / 20: 4 n-6)$, the ratio $n-3 L C P / n-6 L C P$, and total trans FA.

\section{Health outcomes}

The outcome variables were based on parents' answers to questions adapted from the International Study on Asthma and Allergy in Children questionnaire, ${ }^{24}$ collected at the ages of 1 and 4 years. We selected eczema at age 1 year and at age 4 years, asthma at age 4 years, and sensitization at age 4 years as indicators of allergic disease. Eczema was defined as an itchy rash that was coming and going during the last 12 months (at folds of the elbows or back of the knee or front of the ankles or in the neck or around eyes and ears) and a doctor's diagnosis of eczema ever. Asthma was defined as doctor's diagnosed asthma ever and either active asthma symptoms in the last 12 months and/or use of asthma medication in the last 12 months. Persistent symptoms were defined as eczema at age 1 year as well as eczema and/or asthma at age 4 years.

At age 4 years, a blood sample was taken in all children who had a home visit at age 3 months who were still participating in the study and whose parents consented to blood sampling. Blood samples were available for 133 of the 256 children in the breast milk study. Specific IgE levels for house dust mite, cat, dog, grass pollen, birch pollen, egg, milk, and Alternaria were measured at Sanquin Research, Amsterdam, using RASTs. Sensitization was defined as specific IgE higher than $0.35 \mathrm{IU} / \mathrm{mL}$ to any of the measured allergens. Sensitized and 
symptoms was defined as being sensitized and having eczema and/or asthma at age 4 years.

\section{Statistical analysis}

Data were analyzed stratified for maternal allergy. Prevalences of symptoms were estimated for low (below the median) and high (above the median) breast milk FA content (wt\%, weight percent of total FA). The associations between FA exposure and health outcomes were furthermore analyzed by logistic regression analysis. Odds ratios (ORs) are presented for an increase in breast milk FA content equivalent to an interquartile range. The following variables were considered as potential confounders: sex, number of older siblings, maternal age, maternal smoking during pregnancy, and maternal body mass index before pregnancy. During the analyses, it appeared that the numbers of cases were too small to assess the effect of the potential confounders in full regression models. These variables were therefore entered 1 at a time into the logistic regression models. Because their inclusion hardly changed the estimates for the associations between breast milk FA and allergic symptoms, only results of the crude analyses are shown.

\section{Results}

In Table I, characteristics of the study population, prevalences of allergic symptoms at age 1 year and age 4 years and breast milk contents of selected FA are shown, stratified for maternal allergy. Breast milk FA content as well as other characteristics were similar in (children of) mothers with and without allergy with the exception of maternal smoking during pregnancy, which was more prevalent in the mothers with allergy. Prevalences of allergic symptoms were higher in children of mothers with allergy than in children of mothers without allergy. Specific IgE was measured in 133 of the 265 children (81 children of mothers with allergy and 52 children of mothers without allergy). There were no significant differences in median breast milk FA contents between children with and children without specific IgE measurement (data not shown). Breast milk samples were obtained between 16 and 247 days after delivery ( $98 \%$ of the samples between 63 and 184 days). There was no correlation between breast milk FA content and the time since delivery when the samples were obtained. 
Table I.

Characteristics of the study population (percentages unless otherwise indicated)

\begin{tabular}{|c|c|c|}
\hline & $\begin{array}{l}\text { Children of } \\
\text { mothers with } \\
\text { allergy, } n= \\
158\end{array}$ & $\begin{array}{l}\text { Children of } \\
\text { mothers } \\
\text { without } \\
\text { allergy, } n= \\
107\end{array}$ \\
\hline Sex (\% boys) & 50.6 & 50.5 \\
\hline Birth weight, g, mean (SD) & $3529(474)$ & $3559(522)$ \\
\hline First child & 53.8 & 53.3 \\
\hline Mother's age, $y$, mean (SD) & $31.2(3.6)$ & $30.7(4.2)$ \\
\hline Father with allergy & 32.3 & 29.0 \\
\hline Breast fed for $\geq 12 \mathrm{wk}$ & 99.4 & 98.1 \\
\hline Time milk sample was collected, days after delivery, mean (SD) & $105(28)$ & $110(30)$ \\
\hline Maternal smoking during pregnancy & 12.0 & 7.5 \\
\hline Eczema at age $1 \mathrm{y}$ & $16.5(26 / 158)$ & $14.0(15 / 107)$ \\
\hline Eczema at age $4 \mathrm{y}$ & $17.1(27 / 158)$ & $16.8(18 / 107)$ \\
\hline Asthma at age $4 \mathrm{y}$ & $8.9(14 / 158)$ & $3.7(4 / 107)$ \\
\hline Persistent symptoms & $12.7(20 / 158)$ & $5.6(6 / 107)$ \\
\hline Sensitization at age $4 \mathrm{y}$ & $39.5(32 / 81)$ & $30.8(16 / 52)$ \\
\hline Sensitization and symptoms at age $4 \mathrm{y}$ & $12.3(10 / 81)$ & $9.6(5 / 52)$ \\
\hline \multicolumn{3}{|l|}{ Breast milk fatty acid content, median wt\% (interquartile range) } \\
\hline LA $(18: 2 n-6)$ & $14.78(5.81)$ & $14.61(4.20)$ \\
\hline AA $(20: 4 n-6)$ & $0.36(0.12)$ & $0.39(0.11)$ \\
\hline$\sum n-6 L C P$ & $1.09(0.33)$ & $1.15(0.29)$ \\
\hline ALA $(18: 3 n-3)$ & $0.90(0.45)$ & $0.97(0.35)$ \\
\hline EPA $(20: 5 n-3)$ & $0.04(0.03)$ & $0.05(0.03)$ \\
\hline DHA $(22: 6 n-3)$ & $0.17(0.11)$ & $0.16(0.10)$ \\
\hline$\sum n-3 L C P$ & $0.49(0.19)$ & $0.49(0.19)$ \\
\hline Ratio ALA /LA (18:3n-3/18:2n-6) & $0.07(0.02)$ & $0.07(0.03)$ \\
\hline Ratio EPA/AA (20:5n-3/20:4n-6) & $0.12(0.08)$ & $0.12(0.09)$ \\
\hline Ratio $n-3 L C P / n-6 L C P$ & $0.44(0.20)$ & $0.43(0.19)$ \\
\hline$\sum$ Trans FA* & $2.63(1.19)$ & $2.62(1.19)$ \\
\hline
\end{tabular}

${ }^{*}$ Trans FA measured were 18:1tr, 16:1n-7tr, and 18:2n-6tr.

\section{Allergic symptoms}

In Table II, the crude prevalences are shown of eczema (at age 1 year and at age 4 years), asthma (at age 4 year), and persistent symptoms (eczema at age 1 year and asthma and/or eczema at age 4 years) for high (above the median, $\mathrm{H}$ ) and for low (below the median, L) contents of selected breast milk FA. For children of mothers without allergy, only prevalences of eczema are shown, because the numbers of children with asthma and with persistent symptoms in this group were too small for analysis ( $n=4$ for asthma and $n=6$ for persistent symptoms). In children of mothers with allergy, high breast milk contents of the different n-3 FA and high n-3/n-6 ratios were generally associated with relatively low prevalences of eczema, asthma, and persistent symptoms. The associations were most pronounced for total $n-3 L C P$ and for the ratio $n-3 L C P / n-6 L C P$. In children of mothers with allergy, relatively low prevalences of allergic disease were also observed in children who had breast milk with a high content of trans FA. In children of mothers without allergy, differences between the eczema prevalences for high and low FA contents were small and inconsistent. 
Table II.

Prevalences of eczema (at age 1 year and at age 4 years), asthma (at age 4 years), and persistent symptoms (eczema at age 1 year and asthma and/or eczema at age 4 years) for high (above the median, $\mathrm{H}$ ) and for low (below the median, L) contents of selected breast milk FA

\begin{tabular}{|c|c|c|c|c|c|c|}
\hline \multirow[b]{2}{*}{ Fatty acid (wt\%) } & \multicolumn{4}{|c|}{ Children of mothers with allergy, $n=158$} & \multicolumn{2}{|c|}{$\begin{array}{l}\text { Children of } \\
\text { mothers without } \\
\text { allergy, } \mathrm{n}=107\end{array}$} \\
\hline & $\begin{array}{l}\text { Eczema } \\
\text { age } 1 \text { y } \\
(\%)\end{array}$ & $\begin{array}{l}\text { Eczema } \\
\text { age } 4 \text { y } \\
(\%)\end{array}$ & $\begin{array}{l}\text { Asthma } \\
\text { age } 4 \text { y } \\
(\%)\end{array}$ & $\begin{array}{l}\text { Persistent } \\
\text { symptoms } \\
(\%)\end{array}$ & $\begin{array}{l}\text { Eczema } \\
\text { age } 1 \text { y } \\
(\%)\end{array}$ & $\begin{array}{l}\text { Eczema } \\
\text { age } 4 \mathrm{y} \\
(\%)\end{array}$ \\
\hline \multicolumn{7}{|l|}{ LA (18:2n-6) } \\
\hline $\mathrm{L}$ & 15.6 & 15.6 & 7.8 & 10.4 & 16.4 & 14.6 \\
\hline $\mathrm{H}$ & 17.3 & 18.5 & 9.9 & 14.8 & 11.5 & 19.2 \\
\hline \multicolumn{7}{|l|}{ AA $(20: 4 n-6)$} \\
\hline $\mathrm{L}$ & 20.7 & 18.4 & 11.5 & 16.1 & 13.3 & 11.1 \\
\hline $\mathrm{H}$ & 11.3 & 15.5 & 5.6 & 8.5 & 14.5 & 21.0 \\
\hline \multicolumn{7}{|l|}{$\sum n-6 L C P$} \\
\hline $\mathrm{L}$ & 15.3 & 17.7 & 8.2 & 11.8 & 10.6 & 12.8 \\
\hline $\mathrm{H}$ & 17.8 & 16.4 & 9.6 & 13.7 & 16.7 & 20.0 \\
\hline \multicolumn{7}{|l|}{$\operatorname{ALA}(18: 3 n-3)$} \\
\hline $\mathrm{L}$ & 20.7 & 22.0 & 9.8 & 17.1 & 16.0 & 16.0 \\
\hline $\mathrm{H}$ & 11.8 & $11.8^{+}$ & 7.9 & 7.9 & 12.3 & 17.5 \\
\hline \multicolumn{7}{|l|}{ EPA $(20: 5 n-3)$} \\
\hline $\mathrm{L}$ & 18.1 & 21.7 & 9.6 & 15.7 & 14.3 & 18.4 \\
\hline $\mathrm{H}$ & 14.7 & 12.0 & 8.0 & 9.3 & 13.8 & 15.5 \\
\hline \multicolumn{7}{|l|}{ DHA $(22: 6 n-3)$} \\
\hline $\mathrm{L}$ & 21.6 & 16.2 & 13.5 & 16.2 & 12.1 & 20.7 \\
\hline $\mathrm{H}$ & 11.9 & 17.9 & $4.8^{\dagger}$ & 9.5 & 16.3 & 12.2 \\
\hline \multicolumn{7}{|l|}{$\sum n-3 L C P$} \\
\hline $\mathrm{L}$ & 22.8 & 22.8 & 11.4 & 19.0 & 11.3 & 17.0 \\
\hline $\mathrm{H}$ & $10.1^{*}$ & $11.4^{+}$ & 6.3 & $6.3^{*}$ & 16.7 & 16.7 \\
\hline \multicolumn{7}{|c|}{ ALA /LA (18:3n-3/18:2n-6) } \\
\hline $\mathrm{L}$ & 16.3 & 21.3 & 8.8 & 15.0 & 15.4 & 15.4 \\
\hline $\mathrm{H}$ & 16.7 & 12.8 & 9.0 & 10.3 & 12.7 & 18.2 \\
\hline \multicolumn{7}{|c|}{ EPA/AA $(20: 5 n-3 / 20: 4 n-6)$} \\
\hline $\mathrm{L}$ & 20.5 & 20.5 & 9.0 & 16.7 & 13.0 & 18.5 \\
\hline $\mathrm{H}$ & 12.5 & 13.8 & 8.8 & 8.8 & 15.1 & 15.1 \\
\hline \multicolumn{7}{|l|}{$n-3 L C P / n-6 L C P$} \\
\hline $\mathrm{L}$ & 23.7 & 22.4 & 13.2 & 19.7 & 14.3 & 19.6 \\
\hline $\mathrm{H}$ & $9.8^{*}$ & $12.2^{+}$ & $4.9^{+}$ & $6.1^{*}$ & 13.7 & 13.7 \\
\hline \multicolumn{7}{|l|}{$\Sigma$ Trans FA } \\
\hline $\mathrm{L}$ & 20.5 & 23.1 & 12.8 & 16.7 & 11.1 & 18.5 \\
\hline $\mathrm{H}$ & 12.5 & $11.3^{*}$ & $5.0^{+}$ & 8.8 & 17.0 & 15.1 \\
\hline
\end{tabular}

$\mathrm{X}^{2}$ Test;

$+.05<P<.10 ;$

${ }^{*} P<.05$.

In Table III, the linear associations are shown between breast milk content of the selected FA and allergic symptoms for children of mothers with allergy. The associations observed were mostly consistent with the results shown in Table II. For LA (18:2n-6), the ORs for different symptoms were consistently above 1 , and for total $n-3 L C P$, the ratio ALA/LA (18:3n-3/18:2n-6), the ratio $n-3 L C P / n-6 L C P$, and for trans FA, ORs were consistently below 1 . The results in Table II and Table III also suggest, for children of mothers with allergy, inverse associations between AA (20:4n-6) and allergic symptoms, but not between total n-6LCP (of which AA is a substantial component) and symptoms. For eczema, substantial and 
statistically significant differences in prevalence were observed for high and low breast milk content of $n-3 L C P$ and $n-3 L C P / n-6 L C P$ ratios (Table II), but the linear associations were weak (Table III). Visual inspection of curves plotted from the restricted cubic spline function showed inverse associations between eczema and $n-3 L C P$ and $n-3 L C P / n-6 L C P$ ratios in the lower part of the exposure distribution, but no association in the higher part of the exposure distribution (plots not shown).

Table III.

Crude ORs (95\% CIs) for the associations between breast milk FA contents and allergic disease in children of mothers with allergy ${ }^{\ddagger}$

\begin{tabular}{|c|c|c|c|c|}
\hline \multirow[b]{2}{*}{ FA (wt\%) } & \multicolumn{4}{|c|}{ Children of mothers with allergy $n=158$} \\
\hline & $\begin{array}{l}\text { OR }(95 \% \mathrm{CI}) \\
\text { eczema age } 1 \text { y }\end{array}$ & $\begin{array}{l}\text { OR }(95 \% \mathrm{CI}) \\
\text { eczema age } 4 \text { y }\end{array}$ & $\begin{array}{l}\text { OR }(95 \% \mathrm{CI}) \\
\text { asthma age } 4 \text { y }\end{array}$ & $\begin{array}{l}\text { OR }(95 \% \mathrm{CI}) \\
\text { persistent } \\
\text { symptoms }\end{array}$ \\
\hline LA $(18: 2 n-6)$ & $1.21(0.76-1.94)$ & $1.25(0.78-1.98)$ & $1.56(0.88-2.76)$ & $1.36(0.82-2.26)$ \\
\hline AA $(20: 4 n-6)$ & $0.62(0.36-1.07)^{\dagger}$ & $0.82(0.48-1.39)$ & $0.74(0.37-1.47)$ & $0.81(0.45-1.48)$ \\
\hline$\sum n-6 L C P$ & $1.12(0.67-1.90)$ & $1.11(0.66-1.85)$ & $1.40(0.71-2.76)$ & $1.26(0.70-2.25)$ \\
\hline $\operatorname{ALA}(18: 3 n-3)$ & $0.67(0.39-1.20)$ & $0.82(0.50-1.35)$ & $0.93(0.50-1.73)$ & $0.66(0.35-1.25)$ \\
\hline EPA $(20: 5 n-3)$ & $0.90(0.65-1.26)$ & $0.90(0.65-1.26)$ & $0.72(0.41-1.26)$ & $0.67(0.41-1.10)$ \\
\hline DHA $(22: 6 n-3)$ & $0.79(0.50-1.23)$ & $0.99(0.70-1.41)$ & $0.39(0.15-0.99)^{*}$ & $0.67(0.37-1.19)$ \\
\hline$\sum n-3 L C P$ & $0.74(0.45-1.21)$ & $0.84(0.54-1.30)$ & $0.50(0.22-1.13)^{\dagger}$ & $0.53(0.27-1.04)^{\dagger}$ \\
\hline ALA/LA $(18: 3 n-3 / 18: 2 n-6)$ & $0.55(0.29-1.04)^{+}$ & $0.64(0.35-1.16)$ & $0.68(0.31-1.48)$ & $0.48(0.23-0.99)^{*}$ \\
\hline EPA/AA $(20: 5 n-3 / 20: 4 n-6)$ & $1.06(0.83-1.37)$ & $0.91(0.68-1.23)$ & $0.79(0.48-1.29)$ & $0.72(0.46-1.14)$ \\
\hline $\mathrm{n}-3 \mathrm{LCP} / \mathrm{n}-6 \mathrm{LCP}$ & $0.82(0.52-1.27)$ & $0.81(0.52-1.26)$ & $0.39(0.16-1.00)^{*}$ & $0.51(0.25-1.03)^{\dagger}$ \\
\hline$\Sigma$ Trans FA & $0.67(0.39-1.13)$ & $0.57(0.33-1.00)^{\dagger}$ & $0.65(0.32-1.33)$ & $0.62(0.33-1.15)$ \\
\hline \multicolumn{5}{|c|}{ Crude ORs ( $95 \%$ CIs) for the associations with different FA in a single model } \\
\hline$\sum \mathrm{n}-6 \mathrm{LCP}$ & $0.98(0.56-1.71)$ & $0.92(0.53-1.60)$ & $1.26(0.62-2.56)$ & $1.09(0.59-2.02)$ \\
\hline$\Sigma$ Trans FA & $0.66(0.38-1.16)$ & $0.56(0.31-1.01)^{\dagger}$ & $0.70(0.34-1.45)$ & $0.64(0.34-1.21)$ \\
\hline$n-3 L C P / n-6 L C P$ & $0.83(0.54-1.27)$ & $0.83(0.55-1.26)$ & $0.44(0.18-1.07)^{+}$ & $0.56(0.29-1.08)^{\dagger}$ \\
\hline$\sum$ Trans FA & $0.67(0.40-1.14)$ & $0.58(0.33-1.01)^{\dagger}$ & $0.71(0.35-1.45)$ & $0.65(0.35-1.20)$ \\
\hline
\end{tabular}

In children of mothers without allergy, logistic regression analysis showed no associations between breast milk FA and allergic symptoms (data not shown).

Evidence for a possible protective effect of total trans FA on allergic symptoms has not been reported previously. To assess the possibility that our findings were influenced by correlations between trans FA and other FA, we investigated our results in some more detail. Breast milk trans FA content was inversely correlated with the n-6LCP content $(r=-0.30 ; P<.0001)$. We found no evidence, however, indicating that $\mathrm{n}-6 \mathrm{LCP}$ content was the underlying determinant of the inverse associations between breast milk trans FA and allergic symptoms. When the total $\mathrm{n}-6 \mathrm{LCP}$ or the ratio $\mathrm{n}-3 \mathrm{LCP} / \mathrm{n}-6 \mathrm{LCP}$ and trans FA were entered simultaneously in a single model, the associations with allergic symptoms were similar to those observed in the models with individual FA (Table III, last 4 rows), indicating independence of the associations. If, in breast milk of mothers with allergy, both the $n-3 L C P / n-6 L C P$ ratio and the trans FA content were below the median $(n=$ 39), symptom prevalences were $31 \%$ eczema at age 1 year, $31 \%$ eczema at age 4 years, $18 \%$ asthma at age 4 years, and $26 \%$ persistent symptoms. If both the 
$\mathrm{n}-3 \mathrm{LCP} / \mathrm{n}-6 \mathrm{LCP}$ ratio and the trans FA content were above the median ( $\mathrm{n}=43$ ), symptom prevalences were $9 \%$ eczema at age 1 year, $9 \%$ eczema at age 4 years, $2 \%$ asthma at age 4 years, and $5 \%$ persistent symptoms.

\section{Sensitization}

In Table IV, the crude ORs are presented for the associations between breast milk FA and sensitization and for the associations between breast milk FA and sensitization in combination with symptoms (the latter only for children of mothers with allergy). As opposed to symptoms, sensitization was not associated with low breast milk contents of n-3 FA, low n-3/n-6 ratios, or low contents of trans FA. In children of mothers with allergy, ORs were close to 1 for most FA, and there was no statistically significant association between sensitization and any of the FA studied (Table IV). In children of mothers without allergy, sensitization was positively associated with breast milk ALA (18:3n-3) content and with the ALA/LA (18:3n-3/18:2n-6) ratio. Similar results were obtained when prevalences of sensitization were compared for low (below the median) and high (above the median) breast milk contents of the selected FA (data not shown).

Table IV.

Crude ORs ( $95 \%$ CIs) for the associations between breast milk FA contents and sensitization at age 4 years, stratified for maternal allergy, and for the associations between breast milk FA contents and sensitization in combination with symptoms (asthma and/or eczema) in children of mothers with allergy ${ }^{\ddagger}$

\begin{tabular}{|l|l|l|l|}
\hline & \multicolumn{2}{|l|}{ Children of mothers with allergy, $\mathbf{n = 8 1}$} & $\begin{array}{l}\text { Children of mothers } \\
\text { without allergy, } \mathbf{n}= \\
\mathbf{5 2}\end{array}$ \\
\hline FA (wt\%) & $\begin{array}{l}\text { OR (95\% CI) } \\
\text { sensitization }\end{array}$ & $\begin{array}{l}\text { OR (95\% CI) } \\
\text { sensitization and } \\
\text { symptoms }\end{array}$ & $\begin{array}{l}\text { OR (95\% CI) } \\
\text { sensitization }\end{array}$ \\
\hline LA (18:2n-6) & $1.03(0.57-1.85)$ & $2.25(1.01-5.02)^{*}$ & $1.14(0.55-2.38)$ \\
\hline AA (20:4n-6) & $0.85(0.50-1.46)$ & $1.23(0.53-2.82)$ & $0.62(0.27-1.39)$ \\
\hline$\sum n-6 L C P$ & $0.78(0.43-1.41)$ & $1.53(0.63-3.71)$ & $0.42(0.18-1.02)^{\dagger}$ \\
\hline ALA $(18: 3 n-3)$ & $0.81(0.49-1.35)$ & $0.70(0.30-1.63)$ & $2.43(1.01-5.88)^{*}$ \\
\hline EPA (20:5n-3) & $0.85(0.55-1.32)$ & $0.56(0.26-1.22)$ & $1.13(0.90-1.43)$ \\
\hline DHA (22:6n-3) & $0.89(0.57-1.38)$ & $0.78(0.36-1.69)$ & $1.10(0.90-1.34)$ \\
\hline$\sum n-3 L C P$ & $0.86(0.52-1.41)$ & $0.48(0.17-1.31)$ & $1.11(0.86-1.42)$ \\
\hline ALA/LA $(18: 3 n-3 / 18: 2 n-6)$ & $0.80(0.43-1.49)$ & $0.23(0.06-0.85)^{*}$ & $2.29(1.01-5.20)^{*}$ \\
\hline EPA/AA $(20: 5 n-3 / 20: 4 n-6)$ & $1.02(0.71-1.46)$ & $0.52(0.23-1.18)$ & $1.22(0.92-1.62)$ \\
\hline$n-3 L C P / n-6 L C P$ & $1.12(0.70-1.77)$ & $0.38(0.12-1.22)$ & $1.29(0.85-1.95)$ \\
\hline$\sum$ Trans FA & $0.90(0.55-1.48)$ & $0.37(0.12-1.17)^{\dagger}$ & $0.94(0.58-1.52)$ \\
\hline
\end{tabular}

${ }^{\dagger} .05<P<.10 ;$

${ }^{*} P<.05$.

${ }^{\ddagger}$ ORs were calculated for an interquartile range increase in breast milk FA content (wt\%).

In children of mothers with allergy, the ORs for sensitization in combination with symptoms showed the same patterns as those for symptoms. The positive association with LA $(18: 2 n-6)$ and the inverse association with the ALA/LA $(18: 3 n-3 / 18: 2 n-6)$ ratio were statistically significant. In the group of mothers without allergy, the number of children with sensitization as well as symptoms was too small $(n=5)$ for analysis. 


\section{Discussion}

In this prospective study, we observed that in susceptible children, the intake of $\mathrm{n}$-3LCP through breast milk was inversely associated with the risk to develop allergic symptoms. Strengths of our study were stratification for maternal allergy, a follow-up period of 4 years and outcomes in terms of symptoms as well as sensitization. Our study had several limitations, which may affect interpretation of the results. Although the number of subjects in our study was larger than the numbers in previous breast milk studies, in children of mothers without allergy, we could not study all endpoints because of small numbers of children with asthma and with persistent symptoms in this subgroup. Also, there were not enough children with symptoms to be able to differentiate between different degrees of symptom severity. The possibility to adjust for potential confounders in the logistic regression analysis was also limited by small numbers.

We have only measured FA in breast milk and we cannot exclude the possibility that other breast milk components are associated with both the breast milk FA content and allergic symptoms in the children, thus confounding the associations we observed. Use of medication by the mothers is another factor on which we have insufficient data, but that could conceivably influence both breast milk composition and allergic symptoms in the children. We followed the children for 4 years, whereas most of the previous studies had a follow-up of 1 year. The presence of allergic symptoms at the age of 4 years, and especially symptoms persisting from age 1 year to age 4 years, are better indicators of allergic disease than symptoms in the first year of life. However, the longer the follow-up period, the larger the variety of factors that may have contributed to the development of symptoms during that period. In particular, the usual family diet might play a role, influencing both the mother's breast milk composition and possibly allergic outcomes in the child. The dietary intake data available in the PIAMA study are not detailed enough to assess intakes of specific FA quantitatively.

\section{N-6 and n-3 FA}

Our study is largely in agreement with findings of earlier breast milk studies on $\mathrm{n}$ 6 and n-3 FA in relation to the development of allergic symptoms. Wright and Bolton $^{13}$ (Zimbabwe, 1989, 25 mothers of children with atopic eczema and 22 controls, cross-sectional) found higher proportions of LA $(18: 2 n-6)$ and of ALA $(18: 3 n-3)$ in breast milk of mothers of children with atopic eczema. The difference in LA (18:2n-6) content was more pronounced and both differences were more marked in children of mothers with a personal history of atopic eczema. Businco et $\mathrm{al}^{14}$ (Italy, 1993, 23 mothers of children with atopic dermatitis and 18 controls, cross-sectional) found that the DHA (22:6n-3) content was significantly lower in milk from mothers whose children developed atopic dermatitis before the age of 6 months than in milk from mothers of healthy children. Duchén et al $^{15}$ (Sweden, 1998, 29 mothers with allergy and 29 mothers without allergy, follow-up 12 months) found that children who had at least 1 positive skin prick test (SPT) in combination with either eczema or asthma in the first year of life had had breast milk (at age 3 months) with a higher $n-6 / n-3$ ratio and a higher $n-6 L C P / n-3 L C P$ ratio than healthy infants. The ratios were highest in allergic infants of mothers with allergy. In a later study (Sweden, 2000, 63 mothers with allergy and 57 mothers without allergy, follow-up 18 months), Duchén et $\mathrm{al}^{16}$ found lower levels of EPA $(20: 5 n-3)$ and DHA (22:6n-3) in breast milk from mothers of children with allergic symptoms and lower levels of EPA $(20: 5 n-3)$ and DHA (22:6n-3) and higher LA/ALA (18:2n-6/18:3n-3), AA/EPA $(20: 4 n-6 / 20: 5 n-3)$, and $n-6 L C P / n-3 L C P$ ratios in breast milk from mothers of children with symptoms and SPT positivity. Kankaanpaa et al ${ }^{17}$ (Finland, 2001, 20 
mothers with allergy and 20 mothers without allergy, follow-up 3 months) found a higher $n-6 / n-3$ ratio in breast milk from mothers of children who were SPTpositive and also had eczema and/or food allergy at age 3 months. This was the case for children of mothers without allergy and not for children of mothers with allergy. Reichardt et $\mathrm{al}^{18}$ (Germany, 2004, 78 children, follow-up 1 year) investigated the FA composition of colostrum (not of mature breast milk) and found no association with atopic eczema or obstructive bronchitis at age 1 year. Children who had developed specific IgE against cow's milk at age 1 had had colostrum with higher median values of LA $(18: 2 n-6)$. The colostrum they had also had a higher median ALA (18:3n-3) content, but this difference was not statistically significant. Stoney et al $^{19}$ (Australia, 2004, 164 mothers with allergy and 60 mothers without allergy, follow-up at 6 months, 12 months and 24 months) did not study allergic symptoms but the development of atopy (SPT positivity) in high-risk children. Higher levels of n-3 FA in colostrum appeared to increase the risk to develop atopy, whereas no associations were observed between the n-3 FA content of breast milk samples collected at the age of 3 months and atopy. The authors discuss various reasons that might explain why their findings seem in conflict with previous studies that suggested a beneficial effect of n-3 FA. Our data show evidence for both these seemingly conflicting findings. In children of mothers with allergy, we observed an inverse association between $n-3 / n-6$ ratios and allergic symptoms, but no associations with sensitization. In children of mothers without allergy, we found a positive association between breast milk ALA (18:3n-3) content and sensitization. On the basis of these results, we suggest that $n-3$ FA and $n-3 / n-6$ ratios may be related to allergic symptoms in a way that is essentially different from the way they relate to sensitization. Our findings and those of Stoney et $\mathrm{al}^{19}$ both suggest that the mechanism by which n-3 FA possibly protects against allergic disease is unlikely to involve the suppression of specific IgE production. The possibility that n-3 FA may even stimulate production of specific IgE deserves further study.

\section{Trans FA}

Our observation that breast milk trans FA content was inversely associated with allergic symptoms (in children of mothers with allergy) is not in agreement with the findings of Weiland et al $^{12}$ from their ecological study. As far as we know, trans FA content of breast milk in relation to the development of childhood allergy has not been studied previously. It has been suggested that trans FA disturb the metabolism of essential PUFA and, in particular, inhibit the biosynthesis of AA $(20: 4 n-6)$ from LA $(18: 2 n-6) .{ }^{25}$ In our study population, the associations with allergic outcomes showed a similar pattern for trans FA and for the $n-3 / n-6$ ratios, suggesting that the 2 factors may affect FA metabolism and the production of inflammatory compounds in a similar way.

\section{Children of mothers with allergy and children of mothers without allergy}

We observed associations between breast milk FA and allergic symptoms in children of mothers with allergy, but not in children of mothers without allergy. Taking maternal allergy as an indicator of the child's predisposition to develop allergic disease, an interpretation of this finding could be that the risk to develop symptoms is modified by FA intake only (or more strongly) in susceptible children. We cannot exclude the possibility, however, that we were unable to detect associations in the group of children of mothers without allergy because of relatively small numbers of children with asthma and with persistent symptoms in this group. The prevalence of sensitization was high (39.5\%) in children of mothers with allergy and did not seem to be influenced by breast milk FA content. 
In children of mothers without allergy, the risk of sensitization was positively associated with breast milk ALA (18:3n-3) content.

In summary, our results provide evidence for the following conclusions. In susceptible infants, relatively high breast milk n-3/n-6 FA ratios may protect against the development of allergic symptoms, but not against sensitization. Trans FA showed a similar effect on symptoms as $n-3 / n-6$ ratios, but this finding needs confirmation in further studies. In low-risk infants, high ALA (18:3n-3) intake may increase the risk of sensitization, but we found no associations between breast milk FA content and symptoms in this subgroup. Our results suggest that the mechanism relating $F A$ intake to sensitization is different from the mechanism relating FA intake to allergic symptoms. This difference-and the differential effects observed in susceptible and nonsusceptible children-may help to explain seemingly conflicting results from different studies conducted so far.

\section{References}

1 N. Novak and D.Y.M. Leung, Diet and allergy: you are what you eat?, J Allergy Clin Immunol 115 (2005), pp. 1235-1237.

2 G. Devereux and A. Seaton, Diet as a risk factor for atopy and asthma, J Allergy Clin Immunol 115 (2005), pp. 1109-1117.

3 N.J. Friedman and R.S. Zeiger, The role of breast feeding in the development of allergies and asthma, J Allergy Clin Immunol 115 (2005), pp. 1238-1248.

4 S.H. Arshad, Primary prevention of asthma and allergy, J Allergy Clin Immunol 116 (2005), pp. 314.

5 L. Hodge, J.K. Peat and C. Salome, Increased consumption of polyunsaturated oil may be a cause of increased prevalence of childhood asthma, Aust N Z J Med 24 (1994), p. 727.

6 P.N. Black and S. Sharpe, Dietary fat and asthma: is there a connection?, Eur Respir J 10 (1997), pp. 6-12.

7 Thien FCK, Woods R, De Luca S, Abramson MJ. Dietary marine fatty acids (fish oil) for asthma in adults and children. The Cochrane Database of Systematic Reviews 2002, Issue 2. Art no: CD001283.

8 S.L. Prescott and P.C. Calder, N-3 polyunsaturated fatty acids and allergic disease, Curr Opin Clin Nutr Metab Care 7 (2004), pp. 123-129.

9 C.B. Stephensen, Fish oil and inflammatory disease: is asthma the next target for $n-3$ fatty acid supplements?, Nutr Rev 62 (2004), pp. 486-489.

10 K.W. Wong, Clinical efficacy of n-3 fatty acid supplementation in patients with asthma, J Am Diet Assoc 105 (2005), pp. 98-105.

11 J. Plat and R.P. Mensink, Food components and immune function, Curr Opin Lipidol 16 (2005), pp. 31-37.

12 S.K. Weiland, E. von Mutius, A. Husing, M.I. Asher and ISAAC Steering Committee, Intake of trans fatty acids and prevalence of childhood asthma and allergies in Europe. ISAAC Steering Committee, Lancet 353 (1999), pp. 2040-2041.

$13 \mathrm{~S}$. Wright and C. Bolton, Breast milk fatty acids in mothers of children with atopic eczema, $\mathrm{Br}$ J Nutr 62 (1989), pp. 693-697.

14 L. Businco, M. Ioppi, N.L. Morse, R. Nisini and S. Wright, Breast milk from mothers of children with newly developed atopic eczema has low levels of long chain polyunsaturated fatty acids, J Allergy Clin Immunol 91 (1993), pp. 1134-1139. 
15 K. Duchén, G. Yu and B. Björkstén, Atopic sensitization during the first year of life in relation to long chain polyunsaturated fatty acid levels in human milk, Pediatr Res 44 (1998), pp. 478-484.

16 K. Duchén, R. Casas, M. Fagerås-Böttcher, G. Yu and B. Björkstén, Human milk polyunsaturated long-chain fatty acids and secretory immunoglobulin $A$ antibodies and early childhood allergy, Pediatr Allergy Immunol 11 (2000), pp. 29-39.

17 P. Kankaanpaa, K. Nurmela, A. Erkkila, M. Kalliomaki, D. Holmberg-Marttila and S. Salminen et al., Polyunsaturated fatty acids in maternal diet, breast milk, and serum lipid fatty acids of infants in relation to atopy, Allergy 56 (2001), pp. 633-638.

18 P. Reichardt, D. Müller, U. Posselt, B. Vorberg, U. Diez, U. Schlink et al. and the Leipzig Allergy Risk Children's Study Group, Fatty acids in colostrum from mothers of children at high risk of atopy in relation to clinical and laboratory signs of allergy in the first year of life, Allergy 59 (2004), pp. 394400.

19 R.M. Stoney, R.K. Woods, C.S. Hosking, D.J. Hill, M.J. Abramson and F.C. Thien, Maternal breast milk long-chain n-3 fatty acids are associated with increased risk of atopy in breastfed infants, Clin Exp Allergy 34 (2004), pp. 194-200.

20 K. Duchén and B. Björkstén, Polyunsaturated n-3 fatty acids and the development of atopic disease, Lipids 36 (2001), pp. 1033-1042.

21 A. Wijga, A.C. Houwelingen, H.A. Smit, M. Kerkhof, A.P. Vos and H.J. Neijens et al., Fatty acids in breast milk of allergic and non-allergic mothers: the PIAMA birth cohort study, Pediatr Allergy Immunol 14 (2003), pp. 156-162.

22 N. Lakwijk, R.T. van Strien, G. Doekes, B. Brunekreef and J. Gerritsen, Validation of a screening questionnaire for atopy with serum IgE tests in a population of pregnant Dutch women, Clin Exp Allergy 28 (1998), pp. 454-458.

23 Foreman-van Drongelen MMHP, van Houwelingen AC, Kester ADM, de Jong AE, Blanco CE. Long chain polyene status of preterm infants with regard to fatty acid composition of their diet: comparison between absolute and relative fatty acid amounts in plasma and red blood cell phospholipids. $\mathrm{Br}$ J Nutr $1995 ; 73: 405-22$.

24 M.I. Asher, U. Keil, H.R. Anderson, R. Beasley, J. Crane and F. Martinez et al., International Study of Asthma and Allergies in Childhood (ISAAC): rationale and methods, Eur Respir J 8 (1995), pp. 483491.

25 T. Decsi and B. Koletzko, Do trans fatty acids impair linoleic acid metabolism in children?, Ann Nutr Metab 39 (1995), pp. 36-41. 